\title{
FABRICATION AND WEAR PROPERTIES OF ZA-27 ALLOY MATRIX HYBRID COMPOSITE REINFORCED WITH NANOPARTICLES
}

\author{
Dr. Fadhil Abbas Hashim, \\ University of Technology, Materials Engineering, Baghdad, Iraq \\ E mail: hashembsb@yahoo.com \\ Dr. Niveen Jamal Abdulkader, \\ University of Technology, Materials Engineering, Baghdad, Iraq \\ E mail: niveen.alwandawy@yahoo.com \\ Kateralnada Faris Hisham \\ University of Technology, Materials Engineering, Baghdad, Iraq \\ E mail: nadaalhyali@gmail.com
}

\begin{abstract}
In this research stir casting technique is used to produce (ZA-27)alloy hybrid composites reinforced by nano particles ( $\mathrm{BN}$ and $\left.\mathrm{Si}_{3} \mathrm{~N}_{4}\right)$ with various weight percentage.The wear test were used pin on disk for both (ZA-27) alloy and all composites. The results indicate that the value of hardness increased with increasing the additives of nano $\left(B N\right.$ and $\left.\mathrm{Si}_{3} \mathrm{~N}_{4}\right)$ percentage for ZA-27 hybrid metal matrix composites. It was found that the nano particles play an important role in improving the wear properties of alloys. Since nano particles impede dislocations movement, causing enhancement in the mechanical properties.
\end{abstract}

Keywords: ZA-27 alloy, Stir Casting, Hybrid Composite, Nanoparticles, Hardness \&Wear Rate.

\section{INTRODUCTION}

Zinc - aluminum alloy (ZA alloys) are widely used in for both scientific researches and industry, as a tribomaterials, due to its good castibility and other properties, which become an alternative alloy for bearing 
bronze [S. S. Owoeye,, et al., 2018]. They are known to be cheap material processed energetically, efficiently and without endangering the environment [ W. K. Meyers, et al. 2003] .

ZA-27 have higher aluminium and copper contents which give high strength, excellent wear and creep resistance, and lower density [ S. C. Krishna, et al. 2006], However, when wear resistance properties are needed, ZA-27 has demonstrated extraordinary performance [ Y. H. ZHU , 1999].

Nowadays, the most researchers studied the properties of the ZA-27 alloy reinforced with ceramic dispersions such as silicon carbide and graphite for improving mechanical and tribological properties[W. K. Krajewski, 2006]. The purpose of applied metal matrix composite based on ZA-27 matrix because its light weight and good mechanical and wear properties [M. Kaplan,, et al..2008] .

The hybrid metal matrix composites contains two or more types of reinforcements. Reinforcements in terms of mixtures of particles, whiskers and fibers with different weight percentage and varying sizes are utilized in metal matrix for multi functional properties [H., J. Looney, et al. 2002].

Seah et al. 1995, investigated that the hardness of artificial aged specimens of ZA-27/Gr increased as compared with as cast alloy.

Babic et al. 2009, tested ultimate tensile stress for ZA-27 alloy and heat treated it, The results showed reduce UTS and hardness with increase in elongation for as cast alloy while for heat treated alloy showed reduction in hardness.

Ranganath et al. 2002 evaluated the effect of weight percentages of $\mathrm{TiO}_{2}$ additives as a reinforced particles on the mechanical properties of ZA-27. The results indicated that the reinforce particles reduced alloy ductility, and improved UTS, yield strength and hardness. Prasad, et al. ,1998, studied the effect of micro structure composition on the tensile property of ZA-27 alloy. Experiments were performed at different strain rates and temperature. The results showed that the tensile strength of the alloy was improved with increase in the strain rate.

The aims of this study is to evalute the mechanical behavior and study the microstructure of ZA-27 alloy by using a recycled alloys produced by stir casting, and to study the effect of hybrid composite with different percentages of nanoparticles on mechanical properties.

\section{METHODS AND MATERIALS}

\section{A. Materials Selection}

\section{a. Matrix Materials}

Matrix material used in this research was ZA-27 which has excellent properties with a wide range of applications .Its chemical analyzes composition is shown in table (I). 
TABLE I. Chemical analyses of ASTM ZA-27 [ 12]

\begin{tabular}{|c|c|c|c|c|c|c|c|}
\hline Element & $\mathrm{Al} \%$ & $\mathrm{Cu} \%$ & $\mathrm{Mg} \%$ & $\mathrm{Fe} \%$ & $\mathrm{Cd} \%$ & $\mathrm{~Pb} \%$ & $\mathrm{Zn} \%$ \\
\hline $\begin{array}{c}\text { Nominal Chemical Comp } \\
\text { standard }\end{array}$ & $25-28$ & $2-2.5$ & $0.01-0.02$ & 0.1 & 0.003 & 0.004 & $\mathrm{Rem}$ \\
\hline $\begin{array}{c}\text { Actual chemical Composition } \\
\text { of ZA-27 alloy }\end{array}$ & 26.23 & 2.17 & 0.013 & 0.054 & 0.0011 & 0.0006 & $\mathrm{Rem}$ \\
\hline
\end{tabular}

\section{b. Nano Boron Nitride and Nano Silicon Nitride as a Reinforcing Materials}

Ceramic powders (nano BN and nano $\mathrm{Si}_{3} \mathrm{~N}_{4}$ ) were used as reinforcement materials for ZA-27alloy. The morphology of raw powders were studied with Scanning Electron Microscopy (SEM) as shown in Fig. 1.

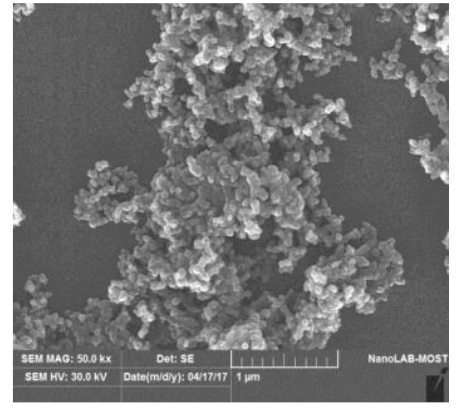

nano BN

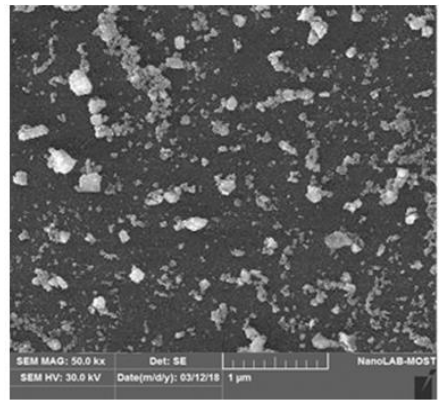

nano $\mathrm{Si}_{3} \mathrm{~N}_{4}$

Fig. 1 SEM of nano (BN and $\left.\mathrm{Si}_{3} \mathrm{~N}_{4}\right)$ powders.

\section{B. Production of Matrix Material and its Composite}

Producing of matrix material (ZA-27alloy) it used The weight of melting alloys was approximately equal to 264 gm , which included $185 \mathrm{gm}$ electrolytic zinc (99.99\%),78 gm pure aluminum , $20 \mathrm{gm}$ master alloy $50 \mathrm{Cu}$ $50 \mathrm{Al}$ and $10 \mathrm{gm}$ AA2024. The melting for all alloys was done in a graphite crucible by using gas furnace to about $700{ }^{\circ} \mathrm{C}$ (above its melting point) to ensure full melting [13]. The molten material was mixed using a mechanical stirrer to get a homogenous mixture. Flux cleaning ( $\mathrm{KCl}-\mathrm{NaCl}-\mathrm{NaF})$ with weight percentage $0.25 \%$ were used which usually rich in chlorides to facilitate wetting of the oxide inclusions for easier separation from the melt. For reducing the impurities and gases by using hexachlorethane as degassing [14]. The reinforcement nanoparticles $\left(\mathrm{BN}, \mathrm{Si}_{3} \mathrm{~N}_{4}\right)$ with different weight percentages were added to the melted matrix as packaged in aluminum foil and continuously stirred using a mechanical stirrer at speed 1000-1200 rpm. to obtain a uniform mixing for all melted material. The slag was removed and then pouring the molten 


\section{AL-QADISIYAH JOURNAL FOR ENGINEERING SCIENCES}

Vol. 11 , No. 4

ISSN: $1998-4456$

material into a cylindrical graphite mold (permanent mold casting) for casting and the temperature was gradually lowered. Fig.2 and Fig.3 show the mold preparation and sketch of mold with dimensions, respectively.
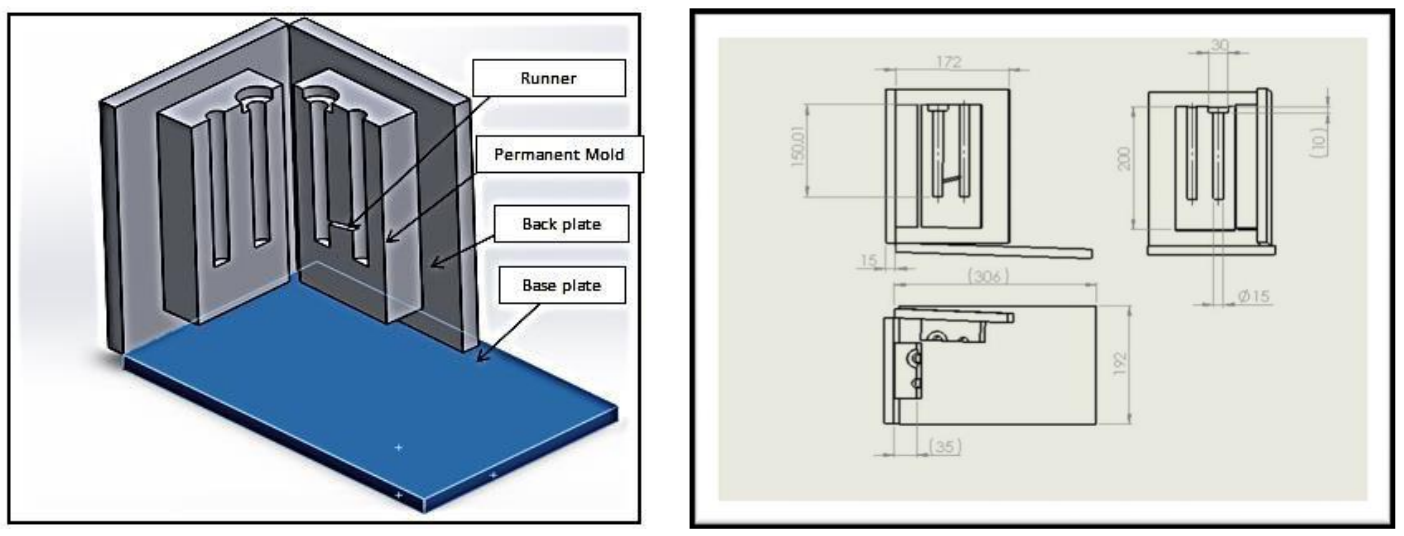

Fig.3 Sketch of mold with Dimensions. (All dimensions are in $\mathrm{mm}$ )

\section{Hardness:}

Hardness test was carried on the base metal alloy and its composites using standard Vickers hardness test machine. The applied load was $0.2 \mathrm{~kg}$. Square based diamond pyramid indenter was used during the test.

\section{Wear test:}

Resistance to surface wear of cast ZA-27 alloy and reinforced with nano boron nitride (BN) and nano silicon nitride $\left(\mathrm{Si}_{3} \mathrm{~N}_{4}\right)$ were evaluated using pin on disc type wear tester as per ASTM G99-95 standards. The sample dimensions were $\Phi 10 \mathrm{~mm}$ with $30 \mathrm{~mm}$ for length. The tests were made using applied load of 5 , $10,15,20 \mathrm{~N}$, the disk rotential speed was $950 \mathrm{rpm}$ and a sliding velocity $6 \mathrm{~cm} / \mathrm{min}$ and for $15 \mathrm{~min}$. The disk was made of stainless steel with $63 \mathrm{HRC}$ hardness.

\section{E. Microstructure:}

Scanning Electron Microscope was used to study the microstructure of ZA-27 alloy and its composites. were investigated by using (Inspect $S 50$ device) and the magnification employed on the samples ranges from 100- 20000X. 


\section{RESULTS AND DISCUSSION}

\section{A. Micro hardness measurement:}

The value of vickers micro hardness are given in figure (4). The results indicate that the hardness of ZA-27 alloy and its composite increased when increasing the weight percentage of nano particles. The presence of hard reinforcement particles ( $\mathrm{BN}$ and $\mathrm{Si}_{3} \mathrm{~N}_{4}$ ) increase load bearing capacity of the composite material and also limit the matrix deformation by impeding the movement of dislocation. The maximum value of hardness were observed at $\left(3 \% \mathrm{BN}\right.$ and $\left.3 \% \mathrm{Si}_{3} \mathrm{~N}_{4}\right)$ weight fraction.

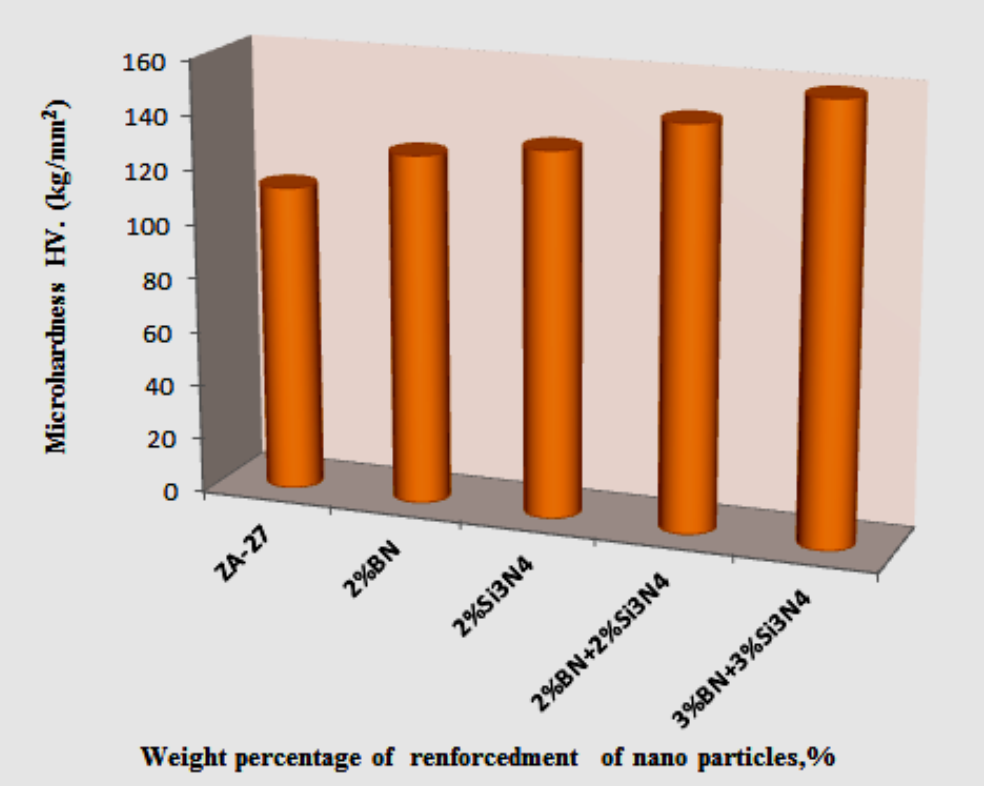

Fig.4 micro hardness values of ZA-27 alloy and its composites.

\section{B. Wear rate measurement:}

The wear rates of composites were increased with increaseing ia addition of nano particles additives as shown in fig (5). Moreover, Increasing the load caused an increase in wear, showing the transition of mild wear to severe wear.

However the transition was more pronounced in alloy compared to composites. Perhaps the increase in reinforcement has resulted in the increased hardness and causes the surface barrier for the penetration of hard particles into the surface. The minimum wear loss was observed for $\mathrm{ZA}-27 / 3 \% \mathrm{BN} / 3 \% \mathrm{Si}_{3} \mathrm{~N}_{4}$ reinforcement compared to other materials studied at all different loads considered in the study.

The wear rate decreasing for hybrid composites with increasing nanoparticles. This due to the presence of both of the reinforcing materials, which assume to form a stable film on surface composites [15]. The nano 


\section{AL-QADISIYAH JOURNAL FOR ENGINEERING SCIENCES}

Vol. 11 , No. 4

ISSN: 1998-4456

ceramic particles improve the hardness and wear properties of the composite, and help in the formation of a stable tribolayer.

The hybrid composites improved the hardness and lower wear rate than the unreinforced matrix.

The wear properties of ZA-27 hybrid composites with nano particles additives as a solids lubricant. The hybrid composites had 3 wt\% BN with $3 w t \% \mathrm{Si}_{3} \mathrm{~N}_{4}$ It was greater mechanical properties than the single reinforced ZA-27 $2 \mathrm{wt} \% \mathrm{BN}$ composite and $\mathrm{ZA}-272 \mathrm{wt} \% \mathrm{Si}_{3} \mathrm{~N}_{4}$.

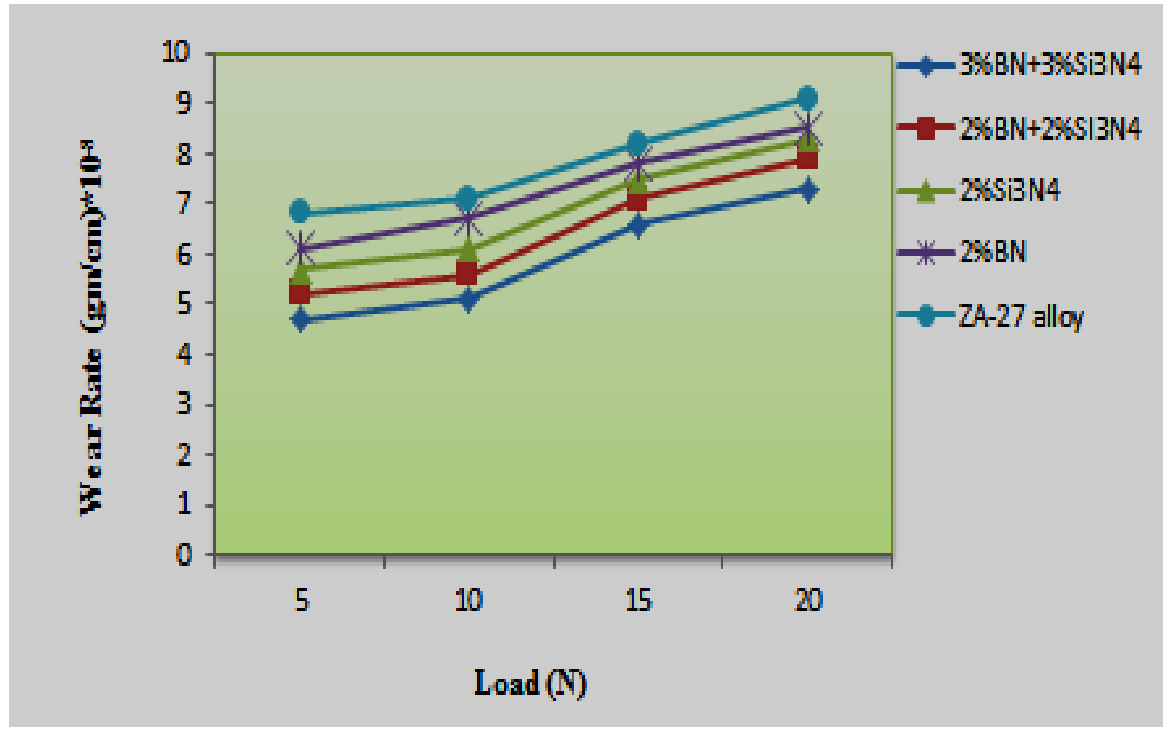

Fig.5 Wear rate values for ZA-27 alloy and its composites of different loads

\section{Microstructure Analysis}

The microstructure was used by SEM. It noticed uniform dispersion of reinforcement in the matrix. The microstructure is dendritic and contributed to fragmented that due to uniform stirring then improving the incorporated and entrapped th nano-sized particles within the interdendritic interface. So the microstructure observed no agglomeration of reinforcement in the matrix that was noticed in Fig (6). 


\section{AL-QADISIYAH JOURNAL FOR ENGINEERING SCIENCES}

Vol. 11, No. 4

ISSN: $1998-4456$

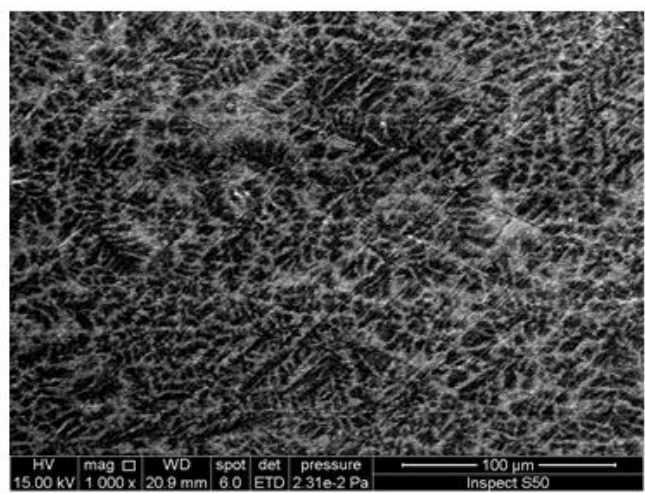

A-

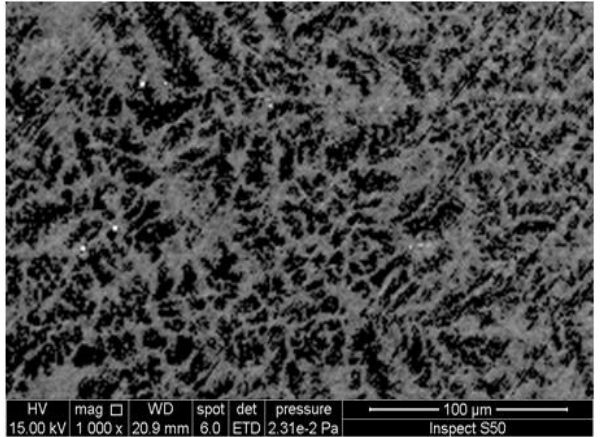

B-

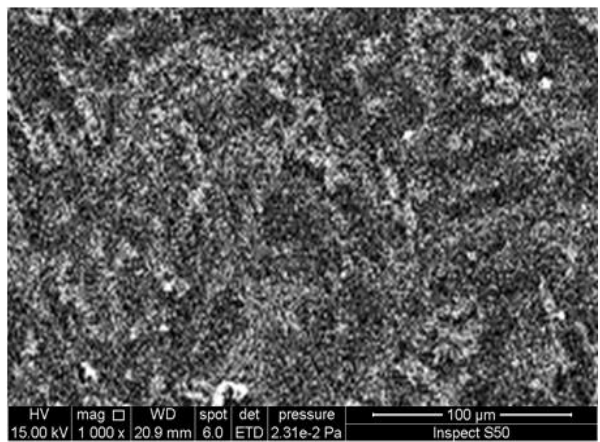

D-

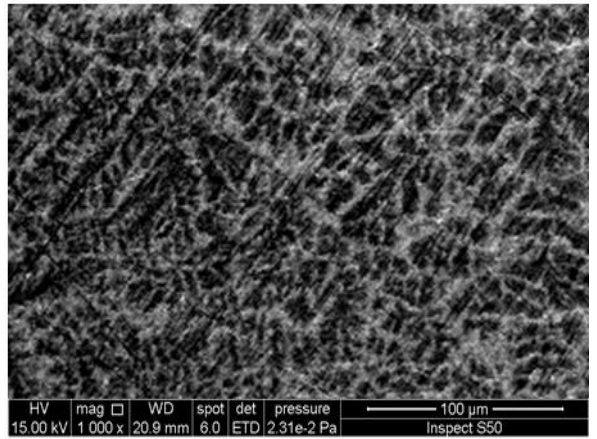

C-

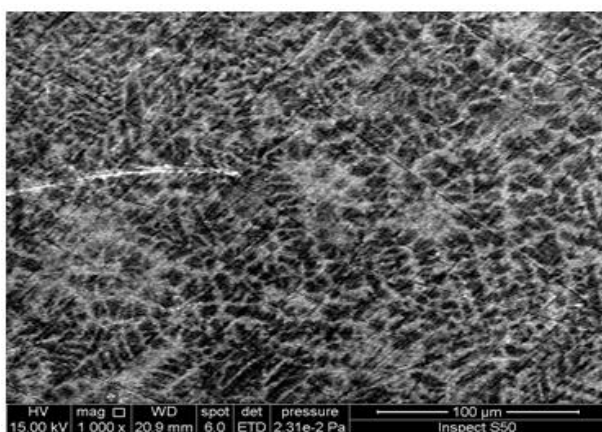

E-

Fig.6 SEM images of ZA-27 alloy- matrix with nano particles at different weight percent.
A) ZA-27 alloy
B) ZA-27 alloy/2\%BN
C) ZA-27 alloy/2\% $\mathrm{S}_{3} \mathrm{~N}_{4}$
D) $Z A-27$ alloy/2\%BN+2\% $\mathrm{Si}_{3} \mathrm{~N}_{4}$
E) $\mathrm{ZA-27}$ alloy/3\%BN+3\% $\mathrm{Si}_{3} \mathrm{~N}_{4}$ 


\section{CONCLUSION}

- The micro hardness values for ZA-27 alloy and composite material was increased with increasing the reinforcement percentage .

- The ZA-27 composite reinforced with $\left(3 \% \mathrm{BN}+3 \% \mathrm{Si}_{3} \mathrm{~N}_{4}\right)$ hybrid nanocomposites exhibited lower wear rate due to presence of two ceramic materials.

- The microstructure of ZA-27 alloy is dendritic structure, and the hybrid composites reinforced with nano particles observed to be uniform distribution and noting to presence the agglomeration particles. Thus, increased nanoparticles with weight percentage increases the mechanical properties of the composite.

- The hybrid composites were cast successfully with liquid metallurgy technique.

\section{REFERENCES}

1- S. S. Owoeye, D. O. Folorunso, B. Oji \& S. G. Borisade,, , "Zinc- aluminum (ZA-27)-based metal matrix composites: a review article of synthesis, reinforcement, microstructural, mechanical, and corrosion characteristics", The International Journal of Advanced Manufacturing Technology", Springer Nature, 2018.

2- W. K. Meyers, "Zinc-Aluminum alloys as tribomaterials" ,Journal Metals, Vol. 22, No. 4, Dec 2003, p. 259.

3- S. C. Krishna, M. Bhattacharyya, "Dry sliding wear behavior of reinforced ZA-27 Alloy based metal matrix composites" International Journal of Modern Physics B, Vol. 20, Issue 25-27, 2006, pp. 47034708.

4- Y. H. ZHU ,"Microstructure dependence of damping behavior of eutectoid $\mathrm{Zn}$-Al based alloy (ZA-27)", J. Mater. Sci. Tech. ,Vol. 15, No.2, 1999.

5- W. K. Krajewski, "Shaping surface wear properties of the Zn-Al based MMCS", Metallurgia Italiana,2006 ,pp 27-30.

6- M. Kaplan, M. Ileriturk, Z. Balalan, "Relationship between microstructure, hardness, XRD and wear performance of cast ZA alloy", Materials and Manufacturing Processes, 2008,pp400-406.

7- H., J. Looney, L. and Hashmi, M.S.J. Particle distribution in cast metal matrix composites-Part I. Journal of Materials Processing Technology, 123(2), 2002, 251-257.

8- S., K.H.W. Sharma, S.C.; and Girish, B.M. Effect of artificial ageing on the hardness of cast ZA27/graphite particulate composites. Materials and Design, 16(6), 1995,337-341.

9- B., M.; Mitrovic, S.; and Ninkovic, R. Tribological Potential of Zinc-Aluminum Alloys Improvement. Tribology in industry, 31(1-2), 2009, 15-28. 
10- R., G.; Sharma, S.C.; Krishna, M.; and Muruli, M.S. , A study of mechanical properties and fractography of ZA-27/Titanium-dioxide metal matrix composites. Journal of Materials Engineering and Performance, JMEPEG, 11(4), 2002, 408-413.

11- P., B.K., Tensile properties of some zinc-based alloys comprising 27.5\% Al: effects of alloy microstructure, composition and test conditions. Materials Science and Engineering: A, 245(2), 1998, 257-266.

12- $\quad$ Annual book of ASTM standers, Standard specification for Zinc alloys in ingot form for foundry casting, Vol. 2.04, B669-84E1, 1988.

13- ASM Handbook, "Casting ", Vol. 15, 1988.

14- K., T. S., M. PRASANNA KUMAR, BASAVARAJAPPA, S., VISHWANATHA, B. M., "MECHANICAL PROPERTIES OF AS-CAST ZA-27/Gr/SiCp HYBRID COMPOSITE FOR THE APPLICATION OF JOURNAL BEARING", Journal of Engineering Science and Technology, Vol. 8, No. 5 2013, 557 - 56.

15- R. Harichandran, and N. Selvakumar, "Effect of h-BN solid nano lubricant on the dry sliding wear behaviour of Al-B4C Nano composites", International Scientific Journal Published Monthly by the World Academy of Materials and Manufacturing Engineering, Vol 77, Issue 1, Pp 5-11, (2016). 